\title{
Assessment of the Content and Utilization of Antenatal Care Services in a Rural Community in Cameroon: A Cross-Sectional Study
}

\author{
Gregory Edie Halle-Ekane ${ }^{1 *}$, Thomas Egbe Obinchemti1, Jeffrey-Lewis Nnomzo'o Nzang2, \\ Ngoe Morike Mokube ${ }^{2}$, Martin Mafany Njie ${ }^{2}$, Theophile Nana Njamen'1, \\ Boniface T. Nasah 1 \\ ${ }^{1}$ Department of Surgery and Gynecology/Obstetrics, Faculty of Health Sciences, University of Buea, Buea, \\ Cameroon \\ ${ }^{2}$ Department of Gynecology and Obstetrics, Regional Hospital Buea, Buea, Cameroon \\ Email: "hallegregory@yahoo.fr
}

Received 23 July 2014; revised 18 August 2014; accepted 15 September 2014

Copyright @ 2014 by authors and Scientific Research Publishing Inc.

This work is licensed under the Creative Commons Attribution International License (CC BY).

http://creativecommons.org/licenses/by/4.0/

(c) (i) Open Access

\section{Abstract}

Background: Pregnant women receive antenatal care (ANC) to ensure favorable pregnancy outcomes. Despite the high ANC coverage rate registered nationally in Cameroon; rural women, women with no formal education and those in the most deprived quintile still face difficulties in having access to quality ANC. The impact of the aforementioned factors on ANC use in the Muea Health Area (MHA) is unknown. The objective of this study was to determine the proportion of women attending ANC and the factors influencing ANC attendance in the MHA. Materials and Methods: This was a community based, analytical, cross sectional survey that involved pregnant women and women with children less than two years old who gave an informed consent or assent. Data were collected using a semi structured questionnaire. EPI info Version 7 and Stat Pac for Windows version 12 ${ }^{\odot}$ 1998-2011 (Stat Pac Inc, Bloomington, USA) were used for data analysis. Associations were considered statistically significant for $p$ values less than 0.05 . Results: Two hundred and twenty women were interviewed. The mean age was 25 years (SD 5.28). Ninety-nine percent of women had at least one ANC visit meanwhile $84.8 \%$ had at least four ANC visits. Only $27.2 \%$ of women booked for ANC in the first trimester. Rural (Maumu) residence was associated with inappropriate ANC attendance (attending less than four times) $\left.\chi^{2}=18.5 ; \mathbf{p}=0.001\right)$. Semi urban women $(87 \%$; $95 \%$ C.I. $=85.10 \%-89.0 \%)$ were more likely to attend four or more sessions than rural (Maumu) women $(60.7 \% ; 95 \%$ C.I. $=44.2 \%-77.3 \%)(p=0.001)$. Participant's educational

\footnotetext{
${ }^{*}$ Corresponding author.
}

How to cite this paper: Halle-Ekane, G.E., Obinchemti, T.E., Nzang, J.-L.N., Mokube, N.M., Njie, M.M., Njamen, T.N. and Nasah, B.T. (2014) Assessment of the Content and Utilization of Antenatal Care Services in a Rural Community in Cameroon: A Cross-Sectional Study. Open Journal of Obstetrics and Gynecology, 4, 846-856. 
level was a significant predictor of early booking for ANC $\left(\chi^{2}=26.8\right.$; $\left.\mathbf{p}=0.0002\right)$. Semi urban women (79.1\%; 95\% C.I. $=\mathbf{7 6 . 0 \%}-\mathbf{8 2 . 2 \% )}$ were significantly more likely to have a vaginal examination done than rural (Maumu) women $(42.1 \% ; 95 \%$ C.I. $=17.5 \%-68.2 \%)(p=0.0001)$. Women who met a doctor during ANC $(84.0 \%$; $95 \%$ C.I. $=80.8 \%-87.0 \%)$ were more likely to have a vaginal examination done than women who only met a nurse or a midwife during ANC $(65.0 \%$; $95 \%$ C.I. $=$ $57.7 \%-71.4 \%)(p=0.002)$. One third of women did not have a vaginal examination performed during ANC. $45.83 \%$ and $47.6 \%$ neither did a stool test nor received an insecticide treated net (ITN) respectively. Conclusion: Women in the MHA start their antenatal care late, so they should be encouraged to book early for antenatal surveillance. Furthermore, efforts should be made to increase the access of these women to quality ANC services and to adequately trained ANC providers.

\section{Keywords}

\section{Assessment, Utilization, Antenatal Care, Preferences, Buea}

\section{Background}

One of the targets of the fifth Millennium Development Goal (MDG 5) which aims at improving maternal health, is to reduce by three quarters between 1990 and 2015 the maternal mortality ratio and achieve by 2015 universal access to reproductive health [1]. Optimizing antenatal care has been advanced as an effective strategy for achieving this goal [2] [3].

In Cameroon, 85\% of pregnant women attended at least one ANC session in 2011 [4]. Sixty percent attended at least four times [5]. Despite this high level of antenatal care coverage several women still lacked access to appropriate pregnancy care [6]-[8], so still died as a result of pregnancy and/or delivery related causes [7] [9]. This necessitates a proper appraisal of the quantitative and qualitative aspects of the antenatal care provided if the maternal mortality ratio is to be reduced.

In Cameroon, community based surveys on ANC utilization are scarce. Most studies on ANC are hospital based and have been centred on accessibility of this service to women [6]-[8]. Moreover, very little has been done to determine the impact of socio-economic factors on ANC attendance.

The aim of this study was to assess the content of ANC services and factors affecting their use in the Muea health area (MHA) a rural community in Buea Health District, Cameroon using a community based approach.

\section{Materials and Methods}

This was an analytical cross sectional, community based study. Participants were recruited during household visits in the area. Ethics clearance was obtained from the Ethical Review Board of Faculty of Health Sciences, University of Buea. The chiefs of the respective localities were consulted before the study was implemented in their community. Participants were interviewed only after signing consent forms. Prospective participants who were less than 21 years, were included only after an assent form was signed by the legal guardian.

The study was conducted in the Muea Health area, a semi urban and rural locality in the Buea Health District of South West Region, Cameroon. It has an estimated population of 32,873 inhabitants made up of subsistence farmers, petty traders and students. The localities included in the MHA are: Muea, Lysoka, Maumu, Upper Bolifamba, Bomaka, WoniaMavio, Mile 17 and Lower Bolifamba (Mile 16) [10] [11].

The Muea Integrated Health Centre is the reference health structure in the health area. It has a General practitioner. It provides ANC services, infant welfare clinic (including immunization), delivery as well as normal outpatient consultations. There are other government and private health facilities in the health area.

\section{Sample Size Calculation and Sampling}

The study population was made up of pregnant women and women with a child equal or less than two years residing in the Muea Health Area during the study period. The sample size was calculated using the formula 
$\mathrm{n}_{\mathrm{o}}=\frac{\mathrm{Z}^{2} \mathrm{p}(1-\mathrm{p}) \mathrm{DEFF}}{\mathrm{e}^{2}}$ [11], where $\mathrm{n}_{\mathrm{o}}$ is the minimal sample size for an infinite population, $\mathrm{Z}$, the standard normal deviate for a 95\% confidence interval, $\mathrm{p}$, the proportion of pregnant women attending at least a visit in the South West Region according to the DHS 2011 [3], e the level of precision and DEFF the design effect for using cluster sampling. With $\mathrm{Z}=1.96 ; \mathrm{p}=91.3 \%$; $=0.05$ and $\mathrm{DEFF}=2$ we have a minimal sample size of 244 participants. Using the finite population correction $n=n_{0} /\left(1+n_{0} / N\right)$ with $n$, the minimal sample size for the MHA; $\mathrm{n}_{0}$, the minimal sample size for an infinite population 244 and $\mathrm{N}$, the estimate of the population of pregnant women in the MHA for 2011; 1644. We obtain $n=212$. We recruited 220 women to account for incomplete responses.

The subjects were recruited by cluster sampling. The health area was divided in quarters and villages (seven in total). These were subsequently divided in blocks of fifty households (clusters). The number of clusters per quarter and village was determined according to its population. This repartition was done following the estimates of the population of each quarter/village as given by the District Health Services [12]. Taking seven individuals per household, the average number of households per community was determined. Seven was taken as number of household's inhabitants from the fact that an average Cameroonian woman will have five children at the end of her reproductive years and if we consider the woman and her husband this gives us averagely seven individuals per household [13]. The number of clusters selected per community was proportional to population size. Boundaries of clusters were determined on the Muea Health Area map. The first household in a cluster was randomly selected. The closest house to the first selected was visited next and so on till the number of eligible participants in a cluster was attained.

Interviews were carried out in English or Pidgin English. In instances where more than one eligible woman was found in a household, only one was selected and the others automatically excluded. Data was collected on certain socio-demographic variables (age, residence, marital status, parity, educational level of participant and partner, monthly income, outcome of previous pregnancies) and outcome variables(number of ANC sessions attended, number of ANC sessions missed, timing of the first ANC visit, activities done during each visit and recommendations given).

Data was analysed with EPI info version 7.0.8.3. Four incomplete questionnaires were excluded from the data analysis. EPI info and Stat Pac for Windows version $12^{\odot}$ 1998-2011 (Stat Pac Inc, Bloomington, USA) were used for analysis. Frequencies were obtained for demographic data as well as ANC attendance. The mean gestational age at first visit was calculated as well as the distribution of women's first visits per trimester. The Chi square test was used to test possible associations between selected demographic variables and ANC attendance as well as timing of first visit. Associations were considered statistically significant for $\mathrm{p}$ values less than 0.05 .

\section{Results}

The mean age of the two hundred and twenty participants was 25 years (SD 5.3). Other socio-demographic characteristics are shown in Table 1.

Two hundred and seventeen (98.6\%) women attended ANC at least once during their last pregnancy while three (1.4\%) did not attend ANC. The mean number of visits was 5 (SD = 2.6). Two women declared they did not attend ANC for financial reasons while one did not attend for religious reasons. A hundred and eighty four women (84.5\%) had four or more ANC visits while 33 (15.2\%) had less than four ANC visits. Fifty nine (27.2\%) women had their first visit in the first trimester. Most women 148 (69.1\%) had their first visit in the second trimester. Eight (3.7\%) women had their first ANC visit in the third trimester. Financial constraints were the most significant barrier to starting ANC early.

Two hundred and nineteen (99.5\%) women found ANC important during pregnancy. Most 155 (70.8\%) women attended ANC to "check their health and that of their child". Other reasons for attending ANC were: learn new things about pregnancy 26 (11.87\%), receive treatment in case of problems 19(8.6\%), have tests done 12 (5.5\%), receive help during pregnancy 4 (1.8\%), confirm pregnancy 3 (1.4\%).

\subsection{Content of Antenatal Care Services}

Some interventions provided during ANC were selected as outcome variables. These included; provision of intermittent presumptive treatment (IPT) for malaria with Sulfadoxine-Pyrimethamine, administration of anti- 
Table 1. Other socio-demographic characteristics of the study population.

\begin{tabular}{|c|c|}
\hline Variables & Frequency (\%) \\
\hline \multicolumn{2}{|l|}{ Residential area } \\
\hline Urban & $12(1.36 \%)$ \\
\hline Semi urban & 179 (80.91\%) \\
\hline Rural & $29(13.18 \%)$ \\
\hline \multicolumn{2}{|l|}{ Women's occupation } \\
\hline Farmers and Petty Traders & $129(58.82 \%)$ \\
\hline Housewives & $60(27.36 \%)$ \\
\hline Civil servants & $15(6.37 \%)$ \\
\hline Other informal jobs & $16(7.45 \%)$ \\
\hline \multicolumn{2}{|c|}{ Participant’s monthly income (Quintiles) } \\
\hline 1 (229 - 285 USD) & $3(1.36 \%)$ \\
\hline 2 (172 - 228 USD) & $3(1.36 \%)$ \\
\hline 3 (115 - 171 USD) & $3(1.36 \%)$ \\
\hline 4 (58 - 114 USD) & 40 (18.18\%) \\
\hline 5 (57 USD) & $171(77.73 \%)$ \\
\hline \multicolumn{2}{|l|}{ Partners' occupation } \\
\hline Petty trader and farmer & $81(36.82 \%)$ \\
\hline Civil servant & 43 (19.55\%) \\
\hline Driver & $28(12.73 \%)$ \\
\hline Builder & 25 (11.36\%) \\
\hline Other informal jobs & 43 (19.54\%) \\
\hline
\end{tabular}

helminthics, having a vaginal examination as well as a stool test done, the provision of insecticides treated bed nets etc. Women attending ANC were asked if some specific activities were carried out during ANC sessions. The content of ANC services is depicted in Table 2.

A hundred and eleven (51.2\%) women received ANC services from a nurse or a midwife meanwhile 106 (48.9\%) met a doctor during ANC. Women were asked if they received health education during ANC. The most frequent health topics discussed during ANC were; the importance of HIV testing during pregnancy 210 (96.8\%), nutrition during pregnancy, medicines that are safe to take during pregnancy and how to take care of a neonate in 199 (92.1\%) cases. The least discussed subjects were; dangers of smoking during pregnancy158 (72.5\%) and contraceptive methods use after pregnancy145 (66.8\%).

As regards motivation for attending ANC, a hundred and seventy one (78.8\%) women declared they decided themselves to attend ANC during their last pregnancies. Thirty three (15.2\%) women declared they were influenced by their partner to attend ANC. For six (2.8\%) women parents were the strongest influence for them to attend ANC. Three women (1.4\%) were encouraged by their sisters and two $(0.9 \%)$ were encouraged by their friends. One woman $(0.5 \%)$ was encouraged to attend ANC by her mother in law.

When women attending ANC were asked why they choose to attend ANC in a particular health structure. Majority of women 75 (34.6\%) choose the ANC centre because it was near to their houses. Other reasons for the 
Table 2. Content of antenatal care services.

\begin{tabular}{cc}
\hline Activity & Frequency (\%) \\
\hline Measurement of weight & $220(100 \%)$ \\
Clinical examination & $219(99.54 \%)$ \\
Urine tests & $219(99.54 \%)$ \\
Blood tests & $219(99.54 \%)$ \\
Blood pressure measurement & $218(99.07 \%)$ \\
Iron/folic acid & $218(99.07 \%)$ \\
Obstetrical examination & $217(98.61 \%)$ \\
Tetanus toxoid immunization & $217(98.61 \%)$ \\
HIV test & $214(97.22 \%)$ \\
IPT (Sulfadoxine-pyrimethamine) & $185(86.05 \%)$ \\
Administration of anthelminthics & $162(75 \%)$ \\
Vaginal exam & $160(74.07 \%)$ \\
Stool test & $117(54.17 \%)$ \\
\hline
\end{tabular}

choice of site were; good services 62 (28.6\%), affinity for the health facility 16 (7.4\%), cheap services 12 (5.6\%).

\subsection{Factors Associated with ANC Utilization or Attendance}

Outcome variables used to assess ANC utilization by women were the number of visits attended, the timing of the first visit and if women missed a visit or not. Age, residence, marital status, parity, participant's educational level and monthly income, partner's educational level and monthly income, and previous pregnancy outcomes were selected as predictor variables. Possible associations were tested with the chi square test and associations with $\mathrm{p}$ values less than 0.05 were considered statistically significant.

Rural (Maumu) residence was associated with inappropriate ANC attendance (attending less than four ANC visits) $\left(\chi^{2}=18.5 ; \mathrm{p}=0.001\right)$. All urban women $(100 \%)$ attended four or more sessions. Semiurban women (87\%; $95 \%$ C.I. $=85.1 \%-88.9 \%$ ) were more likely to attend four or more sessions than rural (Maumu) women $(60.7 \%$; 95\% C.I. $=44.2 \%-77.3 \%)(\mathrm{p}=0.001)$.

Participant's educational level, age, parity, marital status, participant's monthly income, partner educational level, partner's monthly income and outcomes of previous pregnancies did not show any significant association with the number of visits, the timing of the booking visit and missing ANC visits (Table 3).

Semi urban women $(79.1 \%$; $95 \%$ C.I. $=76.03 \%-82.2 \%)$ were significantly more likely to have a vaginal examination done than rural (Maumu) women $(42.1 \%$; 95\% C.I. $=17.5 \%-68.2 \%)(\mathrm{p}=0.0001)$ (Table 4). Women who met a doctor during ANC (84.0\%; 95\% C.I. $=80.8 \%-87.1 \%)$ were more likely to have a vaginal examination done than women who only met a nurse or a midwife during ANC $(65.00 \%$; $95 \%$ C.I. $=57.7 \%$ $71.4 \%)(\mathrm{p}=0.002)$.

Predictor variables were the residence, type of health institution attended and the ANC provider met (Table 5).

There was an association between the type of health institution attended and the provision of insecticides treated bed nets. Seventy four percent of women attending ANC in government health institutions were more likely to benefit from an ITN than twenty nine percent of women attending ANC in private health institutions, $\chi^{2}$ $=17.5 ; \mathrm{p}=0.006$ (Figure 1$)$. 
Table 3. Factors influencing the number of ANC visits attended.

\begin{tabular}{|c|c|c|c|c|c|}
\hline Predictor variable & Less than four visits & Four visits or more & Total & $\begin{array}{c}\text { Chi square value } \\
\text { (corrected) }\end{array}$ & $\mathrm{p}$ value \\
\hline \multicolumn{6}{|l|}{ Age } \\
\hline $14-19$ & 5 (17.25\%) & 25 (82.75\%) & 30 & \multirow{3}{*}{3.418} & \multirow{3}{*}{0.1811} \\
\hline $20-29$ & $25(17.41 \%)$ & 118 (82.39\%) & 143 & & \\
\hline $30-43$ & $3(6.53 \%$ & 44 (93.47\%) & 47 & & \\
\hline \multicolumn{6}{|l|}{ Residence } \\
\hline Rural & $13(39.28 \%)$ & $19(60.72 \%)$ & 32 & \multirow{3}{*}{18.461} & \multirow{3}{*}{0.001} \\
\hline Semi urban & $22(13 \%)$ & 154 (87\%) & 182 & & \\
\hline Urban & $0(0 \%)$ & $12(100 \%)$ & 12 & & \\
\hline \multicolumn{6}{|l|}{ Parity } \\
\hline 0 & $3(60.0 \%)$ & $2(40.0 \%)$ & 5 & \multirow{4}{*}{6.72} & \multirow{4}{*}{0.0814} \\
\hline $1-2$ & $22(15.27 \%)$ & 122 (84.73\%) & 144 & & \\
\hline $3-4$ & $8(14.28 \%) 2$ & $42(85.72 \%)$ & 50 & & \\
\hline $5-8$ & (9.52\%) & 19 (90.48\%) & 21 & & \\
\hline \multicolumn{6}{|l|}{ Educational level } \\
\hline None & $0(0 \%)$ & $3(100 \%)$ & 3 & \multirow{4}{*}{5.826} & \multirow{4}{*}{0.1204} \\
\hline Primary & 20 (21.97\%) & 72 (78.03\%) & 92 & & \\
\hline Secondary & $10(10.52 \%)$ & 86 (89.48\%) & 96 & & \\
\hline University & 3 (10.715) & $26(89.28 \%)$ & 29 & & \\
\hline \multicolumn{6}{|l|}{ Partner's educational level } \\
\hline None & $0(0 \%)$ & $1(100 \%)$ & 1 & \multirow{5}{*}{6.912} & \multirow{5}{*}{0.1406} \\
\hline Primary & $14(23.72 \%)$ & 46 (76.28\%) & 60 & & \\
\hline Secondary & $10(9.70 \%)$ & 94 (90.3\%) & 104 & & \\
\hline University & $4(23.52 \%)$ & 33 (86.48\%) & 38 & & \\
\hline Don’t know & $4(23.52 \%)$ & $13(76.48)$ & 17 & & \\
\hline \multicolumn{6}{|c|}{ Outcome of previous pregnancies } \\
\hline Abortion & $2(12.5 \%)$ & $14(87.55 \%)$ & 16 & \multirow{3}{*}{5.582} & \multirow{3}{*}{0.0614} \\
\hline Stillbirth & $2(40 \%)$ & $3(60 \%)$ & 5 & & \\
\hline Neonatal death & $0(0 \%)$ & $13(100 \%)$ & 13 & & \\
\hline
\end{tabular}

$\chi^{2}=26.802 ; \mathrm{p}=0.0002$.

Table 4. Factors influencing the provision of vaginal examination during ANC services.

\begin{tabular}{lccc}
\hline \multicolumn{1}{c}{ Predictor variable } & Yes & No & $\chi^{2}$ (corrected) \\
Residence & $12(42.86 \%)$ & $16(57.14 \%)$ & 0.0001 \\
Rural & $141(79.11 \%)$ & $35(19.89 \%)$ & $5(41.67 \%)$ \\
Semi urban & $7(58.33 \%)$ & & \\
Urban & & $17(16.04 \%)$ & 9.099 \\
Level of training of ANC provider & $89(83.96 \%)$ & $39(35.45 \%)$ & 0.0019 \\
Doctor & $71(64.55 \%)$ & \\
Nurse/midwife &
\end{tabular}


Table 5. Factors influencing the provision of stool tests during ANC.

\begin{tabular}{|c|c|c|c|c|}
\hline Predictor variable & Yes & No & $\chi^{2}$ (corrected) & $\mathrm{p}$ value \\
\hline \multicolumn{5}{|l|}{ Residence } \\
\hline Rural & 7 (21.43\%) & $22(78.57 \%)$ & \multirow{3}{*}{7.719} & \multirow{3}{*}{0.02} \\
\hline Semi urban & $87(50.57 \%)$ & $87(49.43 \%)$ & & \\
\hline Urban & $7(50 \%)$ & $6(50 \%)$ & & \\
\hline \multicolumn{5}{|l|}{ Health institution attended } \\
\hline Government health center & $58(40.84 \%)$ & $84(59.16 \%)$ & \multirow{4}{*}{9.975} & \multirow{4}{*}{0.02} \\
\hline Faith Based organization & $15(46.88 \%)$ & $17(53.12 \%)$ & & \\
\hline Private clinic & $21(72.41 \%)$ & $8(27.59 \%)$ & & \\
\hline Regional hospital & $5(38.46 \%)$ & 8 (61.54\%) & & \\
\hline \multicolumn{5}{|c|}{ Qualification of training of ANC provider } \\
\hline Doctor & $60(56.6 \%)$ & $46(43.4 \%)$ & \multirow{2}{*}{8.8925} & \multirow{2}{*}{0.002} \\
\hline Nurses/Midwife & $39(35.45 \%)$ & 71 (64.55\%) & & \\
\hline
\end{tabular}

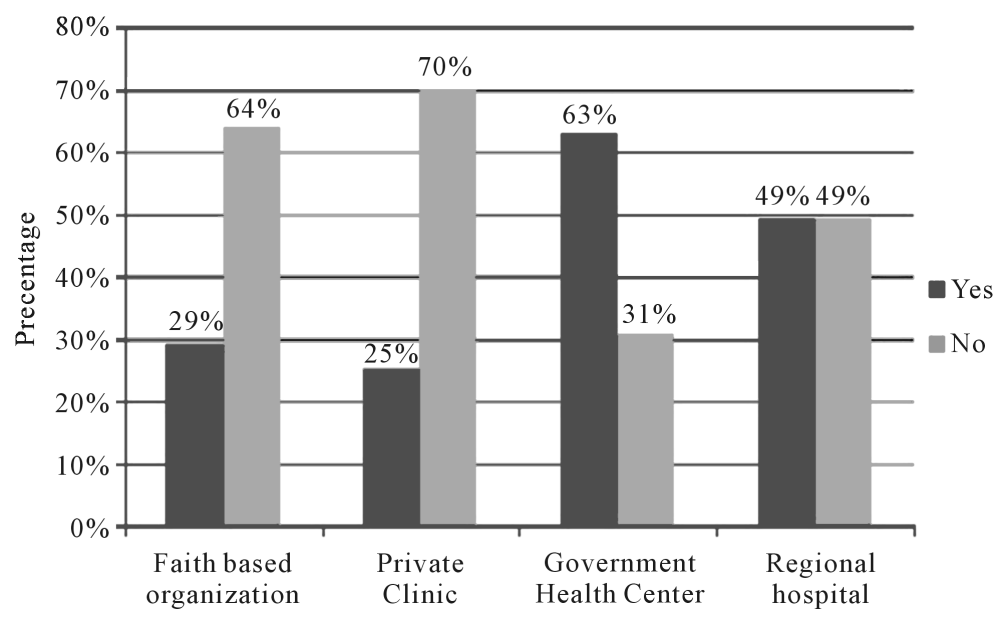

Figure 1. Shows the relationship between the provision of insecticide treated bed nets during ANC and the type of health institution.

\section{Discussion}

This study assessed the content of ANC services and factors affecting the use of these services in a rural setting of the Buea Health District, Cameroon.

Ninety eight percent of women had at least one ANC visit during their last pregnancy. This is similar to the 91.3\% ANC attendance rate in Buea Health District in 2010 [14]. Jimoh [15], in a study in Equatorial Guinea found that $92.5 \%$ of women attended ANC in their last pregnancy. Van Eijk et al. (2006) [16] also found that $90 \%$ of women in a community based study in rural western Kenya had at least one ANC visit during their last pregnancy. Almost $85 \%$ of women in our study had at least four ANC visits. This is higher than the $62 \%$ registered nationally during the DHS 2011 [4].

In this study rural (Maumu) women were more likely to have less than four visits than urban and semi urban women. This corroborates the findings of the DHS 2004 in which only 48.4\% of rural women had four or more ANC visits against 78.4\% for urban women [17]. Dairo and Owoyokun [18] found that women from the rural parts of Ibadan were less likely to attend ANC than women in urban settings.

Carlson et al. [19] also documented that in Niger, Chad and Mali residence was a strong predictor of ANC attendance. The four visits model has been recommended by WHO as it has been shown to be associated with a 
desirable or good foeto-maternal outcome even in a low income setting when the guidelines of ANC are respected [3].

Only $27.2 \%$ of women started ANC in the first trimester. This is similar to the proportion of women that booked for ANC in the first trimester (31.8\%) in the Yaoundé Central Hospital in 2006 [20]. It is also close to the proportion of women (35\%) who had their first ANC visit before four months in the DHS 2004. In a study done in Entebbe, a Semi urban locality of Uganda Tann et al. [21] found that only 16\% of women have their first visit in the first trimester. In another study in rural Uganda this time, Kiwuwa and Mufubenga [22] found that $57.7 \%$ of women booked for ANC in the first trimester. The finding of our study was similar to those of Ali et al. [23] in Kassala, Eastern Sudan where 31\% of women booked for ANC in the first trimester. One can therefore observe that late booking for ANC is a common tendency across sub Saharan Africa. Late ANC attendance may preclude women from benefiting from preventive strategies such as iron and folic/acid supplementation, treatment of helminthic infections and intermittent preventive treatment (IPT) of malaria using sulfadoxinepyrimethamine thus leading to adverse pregnancy outcomes [18].

Fifty one percent of women were attended to by a doctor during ANC meanwhile $48.9 \%$ were attended by a Nurse/Midwife. This is quite different from the finding of the DHS 2004 [17]. Nationally, only $16 \%$ of women meet a doctor during ANC. The relatively high proportion of women who were attended to by a doctor during ANC in this study might be explained by the fact that there were many readily accessible health facilities near MHA where doctors provided ANC.

The majority of women attending ANC (greater than 98\%) had weight measurement, general and obstetric examination (abdominal palpation and auscultation of foetal heart tones), blood and urine tests, blood pressure measurement, iron, folic acid and tetanus toxoid administration. This ties with the findings of other studies in sub Saharan Africa where more than 70\% of the womenreceived the above interventions [17]-[23]. Van Eijk et al. found that at least $90 \%$ of women in rural western Kenya had abdominal palpation, tetanus immunization and weight measurement. However, only $67.4 \%$ had blood pressure measurement, 53.1\% received iron supplementation, $49 \%$ had their hemoglobin level measured and only $14.4 \%$ had urine tests done [16].

Eighty six percent of women received IPT. This is close to the 90.1\% reported by Anchang-Kimbi et al. [24] in Mutengene and to the $69.71 \%$ found by Takem et al. in Buea [25]. Our results were however higher than the $60 \%$ registered nationally in the DHS 2004 [17].

Anti-helminthics, vaginal examination, stool tests and the provision of insecticides treated bed nets (ITN) were the interventions that women received least (75\%, 74.07\%, 54.17\% and 52.36\% respectively). Van Eijk et al. found that only $2.6 \%$ of women received anti-helminthics, meanwhile $12.6 \%$ stool tests done [16]. Takem et al. found that $15.43 \%$ of women used insecticides treated nets (ITNs) during the gestation period in Buea [25].

There was a significant association between the type of health facility attended and the provision of ITNs. This may be due to the fact that during the study period ITNs were given freely to pregnant women attending ANC in government health facilities while this was not the case in private health structures.

There was also a significant association between vaginal examination evaluation and the professional level of the attending personnel. Women who were attended to by a doctor during ANC were more likely to have benefited from a vaginal examination than those who were attended to by a nurse/midwife. It is interesting to note that since 1987 midwifery schools were closed in Cameroon. Training of midwives was replaced with the training of reproductive health nurses in 2006 with no real success [26]. This can explain the lapses in the ANC provided by this category of staff in the MHA. With the re-launching of midwifery training in September 2011 one can expect a change in the situation.

All women who attended ANC said they received some form of health education during ANC. More than $90 \%$ of women declared that the importance of HIV testing in pregnancy, nutrition during pregnancy, medicines that are safe to take during pregnancy and how to take care of a newborn baby were discussed during ANC. These results are similar to those found by Dairo and Owoyokun in Ibadan [18], Oladapo et al. [27] in South Western Nigeria where $97.1 \%$ and $85.6 \%$ of women respectively who attended ANC received similar information. On the contrary, Gross et al. found that in the Kilombere valley, South Eastern Tanzania only 19\% of women had information on the appropriate diet in pregnancy, meanwhile $28 \%$ had HIV counselling and 3\% had information on medicines safe to use in pregnancy [28]. On other information received, like on the danger signs during pregnancy our findings of $82 \%$ were similar those of $86.6 \%$ documented by Dairo and Owoyokum [18] but different from those of Gross et al. [28] and Ouma et al. [29] where only 3\% and 10\% respectively had this information. 
Contraception was the least discussed topic during ANC. Only $66.82 \%$ of women received information on contraception during ANC. This percentage is lower than in studies carried out by Dairo and Owoyokun in 2010 (90.6\%) and Oladapo et al. in 2008 (81.6\%) [18] [27]. Gross et al. and Ouma et al. had even lower proportions of $8 \%$ and $7.5 \%$ respectively [28] [29]. ANC is considered as an opportunity to reach out to women with information on contraception so that after delivery they will be able to apply the methods of contraception learned. Some women reported that some ANC centres do not give education on contraception because they already provide it during post natal clinics. This may not be enough as a good number of women do not attend post natal clinics. Contraception should be taught during ANC and emphasis should be laid on the contraceptive effect of exclusive breastfeeding which has the advantage of being safe, free and culturally accepted in our region.

The importance of this information and carrying out these health activities cannot be over emphasized with regards to improving pregnancy outcome especially in a low income setting like ours.

The study had some limitations because women whose last pregnancy resulted in a miscarriage or stillbirth were excluded from the study. This was because it was psychologically traumatizing to question them on such sad memories. Furthermore, these women were difficult to identify in communities as pregnancy loss or child death is often considered a taboo topic. They could however be different from our participant population thus introducing some selection bias in our study. Another potential source of selection bias in our study is the fact that we selected just one eligible participant per household. However, in addition to the fact that our sampling method was random, people living in the same household were likely to have the same characteristics particularly socioeconomic status.

\section{Conclusions}

A high proportion of women (98.60\%) attend ANC when pregnant in the MHA probably because of the accessibility to other health facilities in the area. However, more than two thirds of women in the MHA book for ANC after the first trimester and rural women were less likely to attend ANC. Place of residence is a strong predictor for early ANC booking. Furthermore, women who were attended to by a doctor during ANC were more likely to benefit from an appropriate evaluation than women who were attended to by a nurse or midwife. Contraception is the least discussed topic during health education in ANC sessions.

Our study has shown that women are attracted to ANC sites with well trained personnel. This should prompt the powers that be to mobilize and ensure appropriate training of health workers. Our results could be generalized to other rural communities in Cameroon and Central Africa.

\section{Acknowledgements}

We wish to thank the administrative and health care providers of the MHA, the chiefs and the couples who participated in the study for their excellent collaboration. Our thanks also go to Drs. Nathacha Yimkap and Ndemazie Bechem for reviewing the manuscript.

\section{Authors' Contribution}

Gregory Halle Ekane contributed in the project conception, analyzing and interpreting data, writing of the manuscript and is the corresponding author. Thomas Egbe Obinchemti contributed in analyzing and interpreting data and proof reading the manuscript. Jeffrey-Lewis Nnomzo'o Nzang contributed in designing the research, collecting, analyzing and interpreting data and drafting of the article. Theophile Nana Djamen and Ngoe Morike Mokube did part of the data analysis and proof read the manuscript. Martin Njie Mafany and Prof Boniface T. Nasah participated in the research conception, data analysis and interpretation and proof read of the manuscript.

\section{Conflict of Interests}

The authors declare they do not have any conflict of interest.

\section{References}

[1] United Nations (2011) The Millennium Development Goals Report 2011. United Nations, New York.

[2] Abou-Zhar, C.L. and Wardlaw, T. (2003) Antenatal Care in Developing Countries: Promises, Achievements, and 
Missed Opportunities: An Analysis of Trends, Levels, Differentials, 1990-2001. World Health Organization, Geneva.

[3] Villar, J. and Bergsjø, P. (2002) WHO Randomized Trial. Manual for the Implementation of the New Model. World Health Organisation, Geneva.

[4] Institut National de La Statistique, Ministère de la Planification de la Programmation du Développement et de L’Aménagement du Territoire \& ORC Macro (2011) Enquête Démographique et de Santé et a Indicateurs Multiples IDSMICS. Rapport Préliminaire. INS, Yaoundé.

[5] Mafany, N.M., Mati, J.K.G. and Nasah, B.T. (1990) Maternal Mortality in the South West Province of Cameroon 1982-1987. Annuals' Universitaires Sciences Santé, 7, 52-69.

[6] Fomulu, J.N., Ngassa, P.N., Nong, T., Nana, P. and Nkwabong, E. (2009) Mortalité Maternelle à la Maternité du Centre Hospitalier et Universitaire de Yaoundé, Cameroun: Etude Rétrospective de 5 ans (2002 à 2006). HSD, 10, 1116.

[7] Fomulu, J.N., Tiyou, K.C., Mbu, R.E., Nana, N.P. and Leke, R.J.I. (2008) Mortalité Maternelle à la Maternité Principale de Yaoundé: Etude Rétrospective de 2001 à 2006. HSD, 9, 86-92.

[8] Optimizing the Use of Antenatal Care Services in Cameroon. http://www.who.int/evidence/sure/FRPBCPNEN.pdf

[9] WHO (2011) World Health Statistics 2011. WHO, Geneva.

[10] Buea District Health Service (2011) Total Population for the Year 2011, Buea. Buea District Health Services, Annual Report 2011.

[11] Bennett, S., Woods, T., Liyanage, W.M. and Smith, D.L. (1991) A Simplified General Method for Cluster Sample Surveys of Health in Developing Countries. World Health Statistics Quarterly, 44, 98-106.

[12] Buea District Health Service (2011) Population Distribution per Community, Buea. Buea Health District Services. Annual Report 2011.

[13] National Institute of Statistics, Ministry of the Economy, Planning and Regional Development (2008) Country Report on Progress in Achieving the Millennium Development Goals. Ministry of the Economy, Planning and Regional Development, Yaoundé.

[14] Buea Health District Service (2010) Report of Health Activities in Buea Health District January to March 2010. Buea Health District Service.

[15] Jimoh, A.A.G. (2003) Utilization of Antenatal Services at the Provincial Hospital Mongomo, Guinea Equatoria. African Journal of Reproductive Health, 7, 49-54. http://dx.doi.org/10.2307/3583288

[16] Van Eijk, A., Bles, H.M., Odhiambo, F., Ayisi, J.G., Blokland, E.I., Rosen, H.D., Adazu, K., Slutsker, L. and Lindblade, K.A. (2006) Use of Antenatal Services and Delivery Care among Women in Rural Western Kenya: A Community Based Study. Reproductive Health, 3, 2.

[17] Institut National de La Statistique, Ministère de la Planification de la Programmation, du Développement et de L’Aménagement du Territoire, ORC Macro (2004) Enquête Démographique et de Santé Cameroun. INS, Yaoundé.

[18] Dario, M.D. and Owoyokun, K.E. (2010) Factors Affecting the Utilization of Antenatal Care Services in Ibadan, Nigeria. Benin Journal of Post Graduate Medicine, 12, 3-13.

[19] Carlson, M., Paintain, L.S., Bruce, J., Webster, J. and Lines, J. (2011) Who Attends Antenatal Care and Expanded Programme on Immunization Services in Chad, Mali and Niger? The Implications for Insecticide Treated Net Delivery. Malaria Journal, 10, 341.

[20] Mbu, E.R., Kongnyuy, E.J., Mbopi-Keou, F.X., Tonye, R., Nana, P.N. and Leke, R.J.I. (2008) Gynaecological Morbidity among HIV Positive Pregnant Women in Cameroon. Reproductive Health, 5, 3.

[21] Tann, C.J., Kizza, M., Morison, L., Mabey, D., Muwanga, M., Grosskurth, H. and Elliott, A.M. (2007) Use of Antenatal Services and Delivery Care in Entebbe, Uganda: Community Survey. BMC Pregnancy and Child Birth, 7, 23.

[22] Kiwuwa, M. and Mufubenga, P. (2008) Use of Antenatal Care, Maternity Services, Intermittent Preventive Treatment and Insecticide Treated Bed nets by Pregnant Women in Luwero District, Uganda. BMC Pregnancy and Childbirth, 7, 44.

[23] Ali, A.A., Osman, M., Abbaker, A.O. and Adam, I. (2010) Antenatal Care Services in Kassala, Eastern Sudan. BMC Pregnancy \& Childbirth, 10, 67. http://dx.doi.org/10.1186/1471-2393-10-67

[24] Anchang-Kimbi, J.K., Achidi, E.A., Nkegoum, B., Sverremark-Ekstrom, E. and Troye-Bloomberg, M. (2009) Diagnostic Comparison of Malaria Infection in Peripheral Blood, Placental Blood and Placental Biopsies in Cameroonian Parturient Women. Malaria Journal, 8, 126.

[25] Takem, E.N., Achidi, E.A. and Ndumbe, P.M. (2009) Use of Intermittent Preventive Treatment for malaria by Pregnant Women in Buea, Cameroon. Acta Tropica, 112, 54-58. http://dx.doi.org/10.1016/j.actatropica.2009.06.007

[26] Mosima, E. (2011) Government to Open 8 Schools for Midwifery Training This Year. Cameroon Tribune. 
[27] Oladapo, T.O., Iyaniwura, C.A. and Sule-Odu, A.O. (2008) Quality of Antenatal Care services at the Primary Care Level in South Western Nigeria. African Journal of Reproductive Health, 12, 71-92.

[28] Gross, K., Schellenberg, J.A., Kessi, F., Pfeiffer, F. and Obrist, B. (2011) Antenatal Care Practices. An Exploratory Study in Antenatal Care Clinics in the Kilombero Valley, South Eastern Tanzania. BMC Pregnancy and Childbirth, 11, 36.

[29] Ouma, P.O., Van Eijk, A.M., Sikuku, E.S., Odhiambo, F.O., Crawdord, S.B., Ayisi, J.G., Kager, P.A. and Slutsker, L. (2010) Antenatal and Delivery Care in Rural Western Kenya: The Effect of Training Health Workers to Provide "Focused Antenatal Care”. Reproductive Health, 7, 1. http://dx.doi.org/10.1186/1742-4755-7-1 
Scientific Research Publishing (SCIRP) is one of the largest Open Access journal publishers. It is currently publishing more than 200 open access, online, peer-reviewed journals covering a wide range of academic disciplines. SCIRP serves the worldwide academic communities and contributes to the progress and application of science with its publication.

Other selected journals from SCIRP are listed as below. Submit your manuscript to us via either submit@scirp.org or Online Submission Portal.
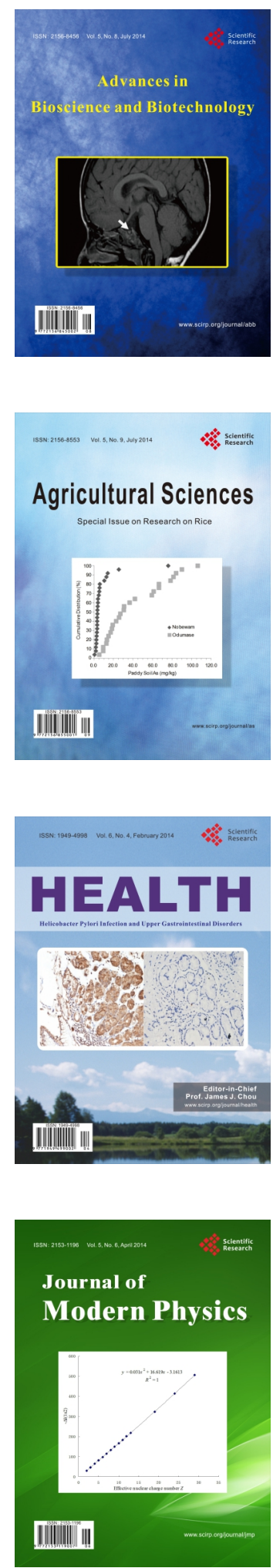
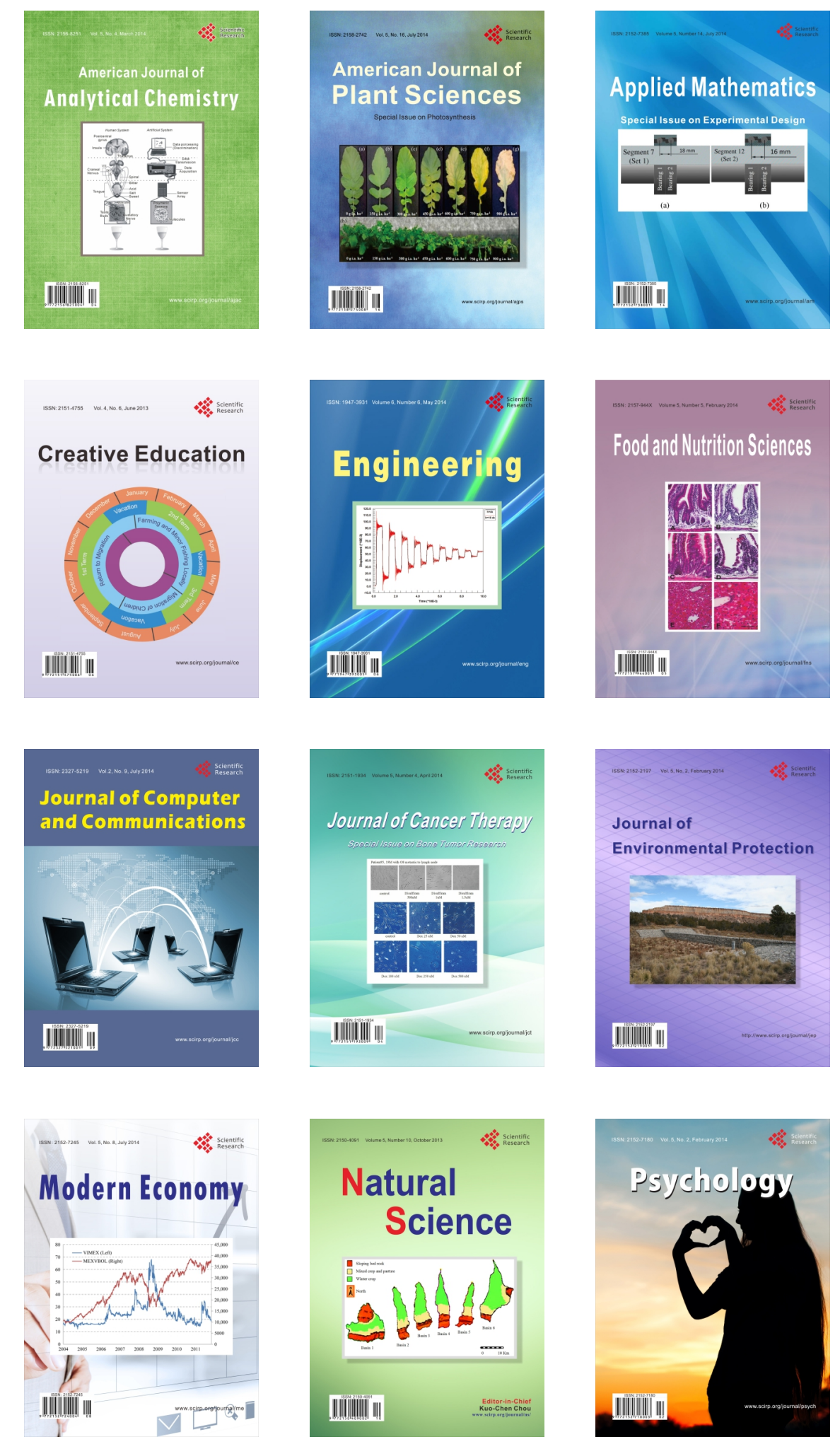